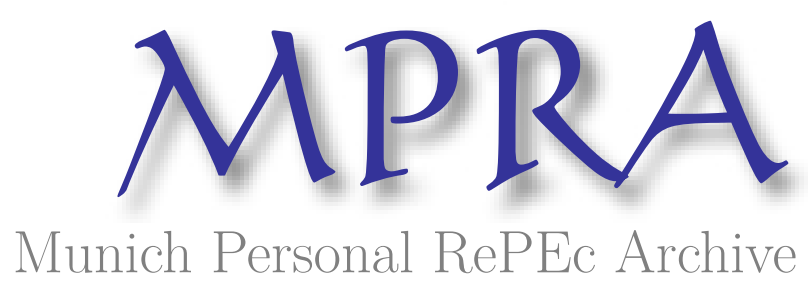

\title{
Population, Affluence, and Environmental Impact Across Development: Evidence from Panel Cointegration Modeling
}

Liddle, Brantley

2013

Online at https://mpra.ub.uni-muenchen.de/52088/

MPRA Paper No. 52088, posted 10 Dec 2013 20:32 UTC 
Population, Affluence, and Environmental Impact Across Development: Evidence from Panel Cointegration Modeling

\author{
Brantley Liddle \\ Senior Research Fellow \\ Centre for Strategic Economic Studies \\ Victoria University \\ Level 13, 300 Flinders Street \\ Melbourne, VIC 8001 \\ Australia \\ btliddle@alum.mit.edu
}

\begin{abstract}
This paper analyzes urban population's and affluence's (GDP per capita's) influence on environmental impact in developed and developing countries by taking as its starting point the STIRPAT framework. In addition to considering environmental impacts particularly influenced by population and affluence (carbon emissions from transport and residential electricity consumption), the paper determines whether and, if so, how those environmental impact relationships vary across development levels by analyzing panels consisting of poor, middle, and rich countries. The development-based panels approach is an improvement on the GDP per capita polynomial model used in the Environmental Kuznets Curve and other literatures for several reasons: (i) it allows one to determine whether the elasticity of all variables considered varies according to development; (ii) it is arguably a more accurate description of the development process; (iii) it avoids potentially spurious regressions involving nonlinear transformations of nonstationary variables (GDP per capita squared); and (iv) unlike the polynomial model, it allows for the possibility that elasticities are significantly different across development levels but still positive - precisely the relationship expected for the environmental impacts considered here. Whether or not the elasticity for affluence was greater than that for population was a function of both the choice of dependent variable and the makeup of the panel (all countries, poor, middle, or rich). Furthermore, the estimated elasticities varied, in a nonlinear fashion, according to the development process: U-shaped, inverted U-shaped, and monotonic patterns were revealed, again, depending on the dependent variable.
\end{abstract}

Keywords: STIRPAT; population and environment; FMOLS panel cointegration; environment and development; IPAT; GHG emissions; Environmental/Carbon Kuznets Curve.

Published in Environmental Modelling \& Software, 40 (2013), 255-266. 


\section{Introduction}

Transport contributes more than one-fifth of global anthropogenic carbon dioxide emissions; the residential sector consumes more than one-quarter of the world's electricity, and transport and residential electricity consumption are increasing in both developed and developing countries. Although there are non-greenhouse gas intensive technologies for generating electricity, two-thirds of electricity is generated from fossil fuels ${ }^{1}$ (of which coal is the largest source). Furthermore, many of those alternatives to fossil fuels also have environmental impacts: wind farms affect bird migrations and are considered by some to be unsightly; hydro-power often involves massive construction-engineering projects, which contribute their own carbon emissions, and can cause displacements of people, wildlife, and ecosystems (e.g., China's Three Gorges dam); and nuclear power raises safety concerns as well as the threat of non-energy, military uses. Also, as normal goods, transport and residential electricity consumption are unlikely to follow an inverted-U path as countries develop/become richer. Lastly, transport and energy in the home are consumed on the individual, household level, and thus, are much more likely than other environmental impacts to be directly influenced by per capita wealth and population.

Population is less likely to directly impact national, aggregate emissions like carbon dioxide; instead, those emissions should be heavily influenced by the structure and energy intensity of the macro-economy (e.g., the presence and size of sectors like iron and steel and aluminum smelting) and by the technologies used to generate electricity (i.e., coal vs. nuclear). For example, smaller in population (by about a third), but very coal-intensive, Australia uses less than half the energy France uses (France relies substantially on nuclear generated electricity); yet, Australia emits seven percent more carbon than France. However, as noted, the majority of transport and all energy in the home are consumed on an individual,

\footnotetext{
${ }^{1}$ US Energy Information Agency projects only a small increase in the share of non-fossil fuels used in electricity generation by 2035 (from 0.32 to 0.35 ), see http://www.eia.doe.gov/oiaf/ieo/index.html.
} 
household level, and thus, are much more likely than national, aggregate emissions to be directly influenced by per capita wealth and population.

This paper employs the stochastic version of the IPAT model (or STIRPAT) in order to examine population's — specifically, urban population's — and affluence's (GDP per capita) influence on carbon emissions from transport and residential electricity consumption in both developed and developing countries. Also, the paper determines whether and, if so, how those environmental impact relationships vary across development levels by analyzing development-based panels consisting of poor, middle, and rich countries and by performing difference in means tests. Finally, the paper employs advanced time-series-based techniques like panel cointegration and panel Fully Modified OLS (FMOLS) to estimate variable elasticities (important since STIRPAT variables are stock or stock-related, and thus, likely nonstationary, and at least population and affluence are potentially inter-related)

\section{Literature review}

\subsection{STIRPAT}

The IPAT/impact equation of Ehrlich and Holdren (1971) is a common framework to distinguish between population's and GDP's (or income's) environmental impact.

Environmental impact (I) is set equal to the product sum of population (P), affluence or consumption per capita (A), and technology or impact per unit of consumption (T). Dietz and Rosa’s (1997) STIRPAT (Stochastic Impacts by Regression on Population, Affluence, and Technology) framework builds on the IPAT equation by allowing hypothesis testing and by not assuming a priori a proportionality in the functional relationships between factors. In general, the STIRPAT model is:

$$
I=a P_{i}^{b} A_{i}^{c} T_{i}^{d} e_{i}
$$

Where the subscript $i$ denotes cross-sectional units (e.g., countries), the constant $a$ and exponents $b, c$, and $d$ are to be estimated, and $e$ is the residual error term. 
Since Equation 1 is linear in log form, the estimated exponents can be thought of as elasticities (i.e., they reflect how much a percentage change in an independent variable causes a percentage change in the dependent variable.) Furthermore, Equation 1 is no longer an accounting identity whose right and left side dimensions must balance, but a potentially flexible framework for testing hypotheses — such as whether elasticities differ across development levels. In addition to determining whether population or GDP has a greater marginal impact on the environment, another important hypothesis to test is whether population's elasticity is different from unity, i.e., whether population or impact grows faster. That hypothesis is particularly interesting/important to test: if population's elasticity is one, then population could be removed as an independent variable via division (from Equation 1), and so the dependent variable would be in per capita terms (the framework used often in nonSTIRPAT analyses, like those in the so-called Environmental Kuznets Curve literature).

The studies applying the STIRPAT formulation to carbon emissions typically found that both population and income/affluence are significant drivers. Furthermore, most studies have found that population has a greater impact (i.e., elasticity) than affluence (e.g., Dietz and Rosa 1997; Shi 2003; York et al. 2003; Cole and Neumayer 2004; Martinez-Zarzoso et al. 2007; Liddle and Lung 2010). However, those studies that sought to determine whether population's elasticity was significantly different from one have produced less consistent results.

For example, Dietz and Rosa (1997), York et al. (2003), and Cole and Neumayer (2004) all found population's elasticity to be statistically indistinguishable from unity (thus, a $1 \%$ increase in population causes an approximate $1 \%$ increase in emissions). By contrast Shi (2003) estimated a particularly high elasticity for population—-between 1.4 and 1.6 for all countries samples; moreover, when Shi separated countries by income groups, the elasticity for high income countries was 0.8 , whereas the elasticity for middle and low income countries 
ranged from 1.4 to 2.0. Similarly, Poumanyvong and Kaneko (2010) estimated population elasticities that ranged from 1.7 to 1.2 to 1.1 for low-income, middle-income, and highincome groups, respectively. Likewise, Martinez-Zarzoso et al. (2007) estimated a statistically insignificant population elasticity for old EU members, but an elasticity of 2.7 for recent EU accession countries. Among the possible reasons for such disparate results are: (i) the different data and methods used (i.e., the time dimension of the data and whether/how the stationarity of the data was considered/addressed); and (ii) whether elasticities were allowed to differ according to development level.

\subsubsection{STIRPAT/stock variables, nonstationarity, and endogeneity}

Most variables used in STIRPAT analyses are stock (population) or stock-related variables (GDP, emissions, and energy consumption, which are influenced by stocks like population and physical capital); as such, those variables are likely nonstationary-i.e., their mean, variance, and/or covariance with other variables changes over time. When OLS is performed on time-series (or time-series cross-section) variables that are not stationary, then measures like R-squared and t-statistics are unreliable, and there is a serious risk of the estimated relationships being spurious. Yet, few STIRPAT studies that employ annual (or more frequent) times-series cross-section (i.e., panel) data have been concerned with the stationarity issue.

Dietz and Rosa (1997) and York et al. (2003) analyzed single-year cross-sections; whereas, Cole and Neumayer (2004), Martinez-Zarzoso et al. (2007), and Poumanyvong and Kaneko (2010) estimated first-difference models to correct for nonstationarity. (Indeed, Cole and Neumayer 2004 hypothesized that the much higher elasticity estimated in Shi 2003 may be spurious because of that paper's use of untreated, nonstationary data.) Although firstdifferencing often transforms nonstationary variables into stationary ones, first-differencing means that the model is a short-run (rather than a long-run) model and that the estimated 
coefficients are constants of proportionality between percentage changes in the independent variables and percentage changes in the measure of impact, rather than elasticities.

As an alternative to taking first-differences, one could test for panel-unit roots (or stationarity) and for panel-cointegration (two or more nonstationary variables are said to be cointegrated if some linear combination of them is stationary), and, depending on the outcome of those tests, estimate the equation via methods like FMOLS. (Such tests were originally designed for time-series but have been expanded to cover panel data sets.) Yet, we know of only one STIRPAT paper to employ these alternative methods_-Liddle (2011).

Pedroni's (2000) FMOLS estimator is designed for panels of cointegrated variables (finding cointegration among economic or economic-related variables is interpreted as evidence of a long-run, equilibrium relationship), and that estimator produces asymptotically unbiased estimates and standard normal distributions free of nuisance parameters. FMOLS accounts for stationarity and corrects for both residual autocorrelation and endogeneity. Addressing the long-run nature of the relationship (i.e., cointegration) among STIRPAT variables, as well as the likely endogeneity among them, is particularly appropriate since such variables are believed to be inter-related and mutually causal according to a number of social science theories. For example, affluence (or GDP per capita) is believed to affect population - through both human capital's influence on birth rates (e.g., Becker et al. 1990) and higher income's ability to lower death rates. Likewise, population has been shown to impact affluence — such as when the size of the working-age population increases faster than the size of the dependent-age population (e.g., Bloom and Williamson 1998); meanwhile, human capital and technology have been recognized as drivers of economic growth (affluence) since Solow (1956). ${ }^{2}$

\footnotetext{
${ }^{2}$ In theory FMOLS accounts for endogeneity among variables implicitly. To more fully and explicitly express the potential mutual feedbacks among the variables would require an approach like multiple structural equation modeling - a discussion of that methodology is beyond the scope of the present paper.
} 


\subsubsection{Differences across development}

Another possible reason for the variation in population elasticity estimates discussed above is that the population elasticity is less than one for advanced/developed/rich countries and greater than one for developing countries. However, Shi (2003) is the only STIRPAT study that sought to determine whether elasticities were significantly different across income/development levels (and Shi only explored this possibility for population's elasticity). (Martinez-Zarzoso et al. 2007 separated their EU panel into new and old members. Both Poumanyvong and Kaneko 2010 and Poumanyvong et al. 2012 separated their panels into three income-based groupings; however, neither paper explicitly determined if the estimated elasticities were statistically significantly different across those groupings.) A few STIRPAT studies have sought to determine whether affluence's elasticity varies according to development by adding a GDP per capita squared term to the regression (e.g., York et al. 2003). We discuss the potential shortcomings of that polynomial/quadratic approach in the coverage of a related literature below.

\subsubsection{Age structure and impact}

A number of researchers, working with micro-level data, have shown that activities like transport and residential energy consumption vary according to age structure and household size (e.g., O’Neill and Chen 2002; Liddle 2004; Prskawetz et al. 2004; and Zagheni 2011). Recently, studies using cross-country, macro-level data have shown a similar relationship (e.g., Liddle and Lung 2010; Liddle 2011). In general, age structure matters because (i) people in different age-cohorts or at different stages of life have different levels of economic activity; and (ii) the age of household head is associated with size of household, and larger households consume more energy in aggregate, although less per person, than smaller households. Liddle and Lung (2010) reviewed the consideration of age structure in STIRPAT analyses; while O’Neill et al. (2012) reviewed STIRPAT studies in general. 
Of that recent, macro-level work, particularly relevant to this paper is Liddle (2011); that paper employed cointegration and FMOLS estimations and considered carbon emissions from transport and residential electricity consumption. However, Liddle (2011) focused on OECD countries only. The level of disaggregation needed to meaningfully analyze population age structure is not available in time series format from the usual international macro-data sources (e.g., United Nations and World Bank) ${ }^{3}$ moreover, such data is not available in time series format from any source for most non-OECD countries. ${ }^{4}$ (Liddle 2011 sourced population data from Eurostat and individual national statistics agencies.)

\subsection{Related literatures}

\subsubsection{Energy-GDP growth}

There is a substantial literature focusing on the relationship between electricity/energy consumption and GDP — sometimes referred to as the electricity/energy-growth nexus (see reviews by Ozturk 2010; Payne 2010a; and Payne 2010b). The studies in this literature (i) tend to analyze multivariate models using macro-level, annual data; (ii) unlike those in the STIRPAT literature, do test for unit roots and cointegration; and (iii) accordingly estimate elasticities with methods like FMOLS. Two multivariate models have emerged as most popular: (i) a production function model, and (ii) a demand model.

In the production function model GDP is a function of electricity/energy consumption, labor/population, and physical capital. After taking logs, the typical panel regression form is:

$$
\ln (G D P)_{i t}=\alpha_{i}+\gamma_{t}+\beta_{1} \ln (E n)_{i t}+\beta_{2} \ln (P)_{i t}+\beta_{3} \ln (K)_{i t}+\varepsilon_{i t}
$$

where $E n$ is energy consumption, $P$ is the population/labor force, and $K$ is capital stock. Most often all variables are left as aggregates, but sometimes the terms of Equation 2 are divided by

\footnotetext{
${ }^{3}$ One needs greater disaggregation than under 15-years and over 64-years; again, see Liddle and Lung (2010) for a discussion.

${ }^{4}$ We leave for future research a panel-style analysis (data observations at 5-10 year intervals, as opposed to timeseries cross-section data) of age structure and environmental impact in less developed countries.
} 
population to convert all variables to per capita (e.g., Lee et al. 2008; and Narayan and Smyth 2008).

Since GDP (or GDP per capita) is the dependent variable, this literature is not interested in evaluating how affluence (or GDP per capita) and population/labor force affect energy consumption (but in evaluating how population/labor force and energy consumption affect GDP); nor is it interested in explaining energy consumption other than to test for socalled Granger causality. ${ }^{5}$ In addition, most of the several papers - that have employed the production function model with panel data, that have tested for panel unit roots and for cointegration, and that accordingly have used methods like FMOLS to estimate elasticitieshave considered single panels (e.g., Narayan and Smyth 2008; Lee et al. 2008; Lee and Chang 2008; and Apergis and Payne 2009a, 2009b, and 2010); and thus, they have not been interested in whether or how those elasticities vary across panels or country groupings. The only such production function study to separate countries into income-based panels was Apergis and Payne (2011), which focused on electricity rather than energy consumption. All of these studies have confirmed that the variables analyzed are panel $I(1)$ and panel cointegrated, and that energy and GDP have an important (significant) and sometimes mutually causal relationship.

Studies employing the demand model explain electricity/energy consumption per capita as a function of GDP per capita and price(s). There is a substantial literature involving single-country analyses aimed at determining the income and price elasticities of gasoline consumption; however, only Liddle (2012) has employed panel data and cointegration modeling to estimate those elasticities. Some additional papers have analyzed residential electricity consumption as a dependent variable, but since time series price data is difficult to obtain (particularly difficult for non-OECD countries), most of them have been single-country

\footnotetext{
${ }^{5}$ A variable, $y$, is said to be "Granger-caused" by another variable, $x$, if $x$ helps in the prediction of $y$. Thus, Granger causality measures precedence and information content, but does not by itself prove causality (that $y$ is the effect or result of $x$ ), any more than any statistical test can prove causality.
} 
studies too (e.g., Holtedahl and Joutz 2004; Halicioglu 2007; Dergiades and Tsoulfidis 2008). The only such panel study to focus on residential electricity consumption, Narayan et al. (2007), considered the G-7 countries only. The equation Narayan et al. examined was:

$$
\ln (E c / P)_{i t}=\alpha_{i}+\gamma_{t}+\beta_{1} \ln (G D P / P)_{i t}+\beta_{2} \ln (E p r)_{i t}+\beta_{3} \ln (G p r)_{i t}+\varepsilon_{i t}
$$

where $E c$ is residential electricity consumption, Epr is the real residential electricity price, and $G p r$ is the real natural gas price.

So again, this literature has not been interested in how/whether elasticities varied across development, nor in whether population had an effect (at least one that was different from unity) on that residential electricity/energy consumption/environmental impact. In addition to determining that the variables were $I(1)$ and cointegrated, all of the above demand model studies confirmed the expected result that income has a positive, significant effect on both gasoline and residential electricity consumption per capita.

\subsubsection{Environmental Kuznets Curve}

There is a (vast) literature that does seek to determine whether the relationship between environmental impact per capita (usually emissions) and income (typically alone) changes with income level—-the Environmental Kuznets Curve (EKC) literature. This literature posits that pollution first rises with income and then falls after some threshold level of income/development is reached, thus forming an inverted U-shaped relationship. One of the main explanations in the literature for the idea that emissions would fall as income rises is that the income elasticity of environmental quality demand is in excess of unity, i.e., a clean environment is a luxury good (Dinda 2004). Thus, one expects that an EKC relationship is most likely to occur for pollutants whose negative impacts are clearly understood, are rather immediate, and can be controlled locally (i.e., the people affected by the pollution can institute policies that will control that pollution). Hence, one would expect that an EKC relationship is less likely for pollutants/environmental impacts whose reach is more global, 
whose damages occur in the future, and whose extent of damages are more uncertain (i.e., carbon emissions).

Empirical studies of the EKC based on panel data typically take the following form:

$$
\ln (E / P)_{i t}=\alpha_{i}+\gamma_{t}+\beta_{1} \ln (G D P / P)_{i t}+\beta_{2}\left(\ln \left(\frac{G D P}{P}\right)\right)_{i t}^{2}+\beta_{3} \ln (Z)_{i t}+\varepsilon_{i t}
$$

where $E$ is emissions and $Z$ is a vector of other drivers that is sometimes, but not always, considered. An EKC between emissions per capita and income is said to exist if the coefficient $\beta_{1}$ is statistically significant and positive, while the coefficient $\beta_{2}$ is statistically significant and negative. Furthermore, when the above situation is the case, the implied turning point - the level of GDP at which the relationship between income and emissions changes from positive to negative — can be calculated by differentiating the estimated equation with respect to GDP per capita, setting the equation equal to zero, and solving.

The empirical evidence on whether a turning point for aggregate carbon emissions exists is mixed (Lieb 2004); whereas, studies that have considered aggregate energy consumption have found a monotonic relationship with income (e.g., Suri and Chapman 1998; Cole et al., 1997). The STIRPAT-based criticism is that if the elasticity of population is not equal to one, then Equation 4 will be mis-specified (since in that case one should not divide both sides of a relationship like Equation 1 by population); in addition to that criticism, reduced form, income driven inverted-U models have been criticized for their (lack of) theory and for their methods, and at least partially discredited when applied to pollution (Stern 2004).

One such objection is to the "... assumption of a causal role of income growth and the inadequacy of reduced-form specifications that presume that a common income-related process ... adequately describes the generation of the pollutant of interest" (Carson 2010, p.5). Similarly, the statistical grouping of countries at different stages of development does not necessarily approximate the actual development process that real countries experience. 
Indeed, Deacon and Norman (2006) used nonparametric methods to examine the incomepollution relationships of individual countries and observed that those within-country relationship patterns did not differ significantly from what would be expected to occur by chance.

Lastly, Stern (2004) argued that many EKC studies risked spurious findings by ignoring that variables like emissions per capita and GDP per capita are likely nonstationary; later, Wagner (2008) argued further that even the EKC studies that did recognize the stationarity properties in the data still risked spurious findings by performing nonlinear (quadratic) transformations of a nonstationary variable (GDP per capita). Indeed, both Wagner (2008) and Stern (2010) determined that if the econometric issues in previous EKC studies are adequately addressed, then the relationships between GDP per capita and both carbon dioxide emissions per capita and sulfur dioxide emissions per capita are (positively) monotonic.

Although we know of no studies that have hypothesized that residential electricity consumption (a normal—not inferior-good) should decline at a certain high level of income, there are a few (cross-country) EKC studies that have focused on transport related environmental impacts. Hilton and Levivson (1998) looked at automotive lead emissions using data for 48 countries over 20 years; they found that despite the fact that gasoline consumption increased with income monotonically, lead emissions and income had an inverted-U shaped relation because pollution intensity (i.e., the amount of lead contained in gasoline) declined with income. Closer to this paper's dependent variable of carbon emissions from transport, Cole et al. (1997) considered per capita energy use in the transport sector in OECD countries over 1970-1990, and determined that energy use increased monotonically throughout the observed income range. Liddle (2004) effectively updated that aspect of the Cole et al. study, by considering per capita road energy use (again in OECD countries) over 
1960-2000, and found an implied turning-point well outside the sample range of income. Thus, the transport-focused EKC studies have confirmed the hypothesis that the demand for mobility (and its associated energy consumption), as a normal good, is unlikely to ever decline with income - its income elasticity may indeed decline at high levels of income, but that elasticity would remain above zero.

\subsection{This paper's contribution}

In addition to analyzing two important, but rather ignored, environmental impactscarbon emissions from transport and residential electricity consumption, this paper advances the STIRPAT literature/framework in several important ways. First, the paper tests the variables analyzed for panel unit roots (or stationarity), and employs advanced time-seriesbased techniques like panel cointegration and panel Fully Modified OLS (FMOLS) to estimate elasticities. These methods are important since STIRPAT variables are both (i) stock or stock-related, and thus, likely nonstationary, and (ii) highly inter-related, and since FMOLS addresses endogeneity among variables. (Again, the only other STIRPAT paper of which we are aware to employ these methods, Liddle 2011, focused on OECD countries only.)

Second, the paper determines whether and, if so, how relationships vary across development levels; it does so by analyzing development-based panels consisting of poor, middle, and rich countries, and by performing difference in means tests. This second innovation is important because few STIRPAT papers have used time-series, cross-section data from developed and developing countries, and we know of only three STIRPAT studies that sought to determine whether elasticities were different across income levels - and only Shi (2003), who explored this possibility for only population's elasticity, determined whether those elasticities were statistically significantly different. None of those three previous studies considered cointegration, and only Poumanyvong and Kaneko (2010) addressed stationarity (via first differencing). Third, the paper focuses on the influence of urban population on 
environmental impact — important because the United Nations expects that over the next 40 years, urban areas will absorb all of the projected 2.3 billion global population growth.

The paper examines a larger cross-section of countries than is typical in the energyGDP nexus literature (albeit by applying a model with possibly fewer explanatory variables than the larger panel necessitates). Also, the paper is different from the energy-GDP nexus literature because it is focused on how GDP per capita and urban population affect environmental impact; again, energy-GDP studies have as the dependent variable GDP (or GDP per capita), and/or they divide the GDP and environmental/energy terms by population, thereby assuming the elasticity of population with respect to impact is unity. Similarly, the paper is different from the Environmental Kuznets Curve literature for not assuming the elasticity of population is equal to one.

Also, the paper contributes to the EKC literature, as well as to the broader literature interested in changes in impact across development levels, by comparing elasticity estimations from panels made up of poor and middle-level developing countries to elasticity estimations from panels of rich/developed countries. Since FMOLS estimated coefficients have asymptotically normally distributed errors, it is a simple calculation to construct confidence intervals (alternatively, one could construct the difference in means test statistic and corresponding, standard normal based, p-value for any pair of panels).

Splitting the countries into development-based panels is a better way to determine whether affluence's (and other factors') environmental impact changes as countries develop, for several reasons. This method allows one to determine whether the elasticity of all variables considered varies according to development, and the separate panel approach is arguably a more accurate description of the development process. The latter point is important because the time dimension of the data typically available is rarely long enough to cover the path of any one country's development from poor to rich (perhaps only Korea's such path can 
be described with the commonly used data). Lastly, the polynomial model used in the EKC and other literatures has been criticized on statistical grounds (by Wagner 2008) since regressions involving nonlinear transformations of nonstationary variables (GDP per capita) could be spurious, and the significance tests based on them invalid. Moreover, that polynomial model does not allow for the possibility that elasticities are significantly different across development levels but still positive - the very phenomenon that the transport-focused EKC literature essentially has argued is the case.

3. Data and panels, empirical specification, methods, and pre-testing results

We use time-series cross-section data spanning 1971-2007 for 31 developed/OECD countries and 54 developing/non-OECD countries. Table 1 displays the variable names and their sources. In addition to an "all countries" panel, we examine panels of rich, middle, ${ }^{6}$ and poor countries of 23,25 , and 37 countries, respectively, roughly divided according to World Bank income level definitions. (The countries comprising those panels are listed in Appendix Table A.1.)

Table 1

Table 2 shows summary statistics for those five variables by each of the three development/income-based panels. Not surprisingly, the means of all the variables except urban population descend with income, i.e., the rich panel has the highest means for environmental impact (transport carbon emissions and residential electricity consumption) and electrification (share electric), the middle panel has the next highest means, and the poor panel has the lowest means. Also, for the variables that are in aggregates (the impacts and urban population), the dispersion (seen by the coefficient of variation as well as the gap

\footnotetext{
${ }^{6}$ The "middle" panel includes less developed OECD countries Mexico and Turkey, former communist OECD countries Czech Republic, Hungary, Poland, and Slovak republic, and OECD countries Korea and Portugal. The inclusion of Korea and Portugal in the middle group is not obvious. Korea's and Portugal's per capita GDP were very much in line with the other countries in this "middle" group until the mid-1980s - when their per capita GDP "broke-away" and ultimately, particularly for Korea, became considerably higher. Essentially, the challenge is categorizing a country as "middle" for a period of 30-plus years, since it is in this very middle group in which one would expect to see movement (in and out) over such a period.
} 
between maximums and minimums) is quite high in all panels. That the dispersion is lowest for share electric (obviously the dispersion on affluence would be low since the panels are constructed by income level) is an indication of the strong association between electrification and development level (the correlation coefficient between affluence and share electric for the entire sample is 0.59 ).

\section{Table 2}

\subsection{Empirical specification}

We consider the environmental impacts of two dependent variables: carbon emissions from transport (i.e., all transport activity from domestic aviation, domestic navigation, road, rail and pipeline transport), and residential electricity consumption. (Liddle and Lung 2010 and Liddle 2011, which both focused on OECD countries, are the only other STIRPAT studies to consider these impacts.) Following others in the literature, we use real GDP per capita as the measure of affluence.

Urbanization has been included in some STIRPAT analyses; however, Liddle and Lung (2010) ultimately determined that urbanization had no effect on carbon dioxide from transport for OECD countries in their STIRPAT regressions. Indeed, Newman and Kenworthy (1989) argued some time ago that transport is negatively correlated with urban density (i.e., the population density of urban areas). ${ }^{7}$ Yet, people living in urban areas are likely to have a greater impact on the environment than people living in rural areas - this is particularly true for residential electricity consumption. Furthermore, most of the population growth - in both developed and developing countries - is occurring in urban areas. Thus, for a population variable we consider urban population, which is constructed by multiplying a country's population by the share living in urban areas (as described in Table 1).

\footnotetext{
${ }^{7}$ Analyzing the available data on the urban density of the world's largest cities, one finds that national urbanization levels are actually negatively correlated with the urban density of those cities $(\rho=-0.59)$.
} 
Also, urbanization may be correlated to the amount of people who are connected to a country's electricity grid — and thus, positively correlated with residential electricity consumption. A more direct measure of access to a country's electricity grid would be electricity's share of residential energy consumption (a variable that was statistically significant in Liddle and Lung's (2010) residential electricity consumption regressions).

Thus, the equation analyzed for residential electricity consumption is:

$$
\ln I_{i t}=\alpha_{i}+\beta_{t}+c \ln P_{i t}+d \ln A_{i t}+f \ln S h E_{i t}+\varepsilon_{i t}
$$

Where subscripts $i t$ denote the $i$ th cross-section and $t$ th time period. The constants $\alpha$ and $\beta$ are the country or cross-section and time fixed effects, respectively. The dependent variable, $I$, is aggregate residential electricity consumption in this case. The $P, A$, and $S h E$ are total urban population, per capita GDP, and electricity's share of residential energy consumption, respectively. Lastly, $\varepsilon$ is the error term. The equation analyzed for carbon emissions from transport is the same as Equation 2 less the $S h E$ term.

Technological advance could impact energy consumption in the transport (and thus carbon emissions) and residential sectors. Insofar as technologies impact similarly throughout cross-sections (i.e., technology diffusion), such impact would be captured by the time fixed effects, and technology diffusion seems a reasonable assumption for panels based on common level of development.

\subsection{Methods}

The first step is to determine whether all the variables are integrated of the same order. $^{8}$ A variable is said to be integrated of order $d$, written $I(d)$, if it must be differenced $d$ times to be made stationary. Thus, a stationary variable is integrated of order zero, i.e., $I(0)$, and a variable that must be differenced once to become stationary is integrated of order one or

\footnotetext{
${ }^{8}$ As mentioned by an anonymous reviewer, technically, each individual cross-sectional series should be $I(1)$; however, because time-series unit root tests have low power - a problem that is exacerbated when the time dimension is short (less than 50) — one cannot convincingly establish that to be the case. Hence, there is a (near) universal convention in the applied literature to rely on panel unit root tests.
} 
I(1). A number of panel unit root tests have been developed to determine the order of integration of panel variables; however, these tests sometimes provide conflicting results. Consequently, we employ four of them.

Im, Pesaran and Shin (2003) developed a test (IPS) that allowed for a heterogeneous autoregressive unit root process across cross-sections by testing a statistic that is the average of the individual (i.e., for each cross-sectional unit) ADF statistics. Maddala and Wu (1999) proposed a panel unit root test based on Fisher (1932) that, like Im et al., allows for individual unit roots, but improves upon Im et al. by being more general and more appropriate for unbalanced panels. Maddala and Wu's test (ADF-Fisher) is based on combining the p-values of the test statistic for a unit root in each cross-sectional unit, is non-parametric, and has a chisquare distribution.

Both of the above tests assume that the cross-sections are independent; yet, for variables like GPD per capita, cross-sectional dependence is possible to likely for panels of similar countries because of, for example, regional and macroeconomic linkages. Pesaran (2007) determined that when cross-sectional dependence is high, the first-generation tests tend to over-reject the null (thus, the main motivation for considering cross-sectional dependence is avoiding the erroneous acceptance of $I(0))$. More recently, panel unit root tests - so-called second-generation tests - have been developed that relax this independence assumption. Among the most commonly used so far is that of Pesaran (2007), which is based on the IPS test, allows for cross-sectional dependence to be caused by a single (unobserved) common factor, and is valid for both unbalanced panels and panels in which the cross-section and time dimensions are of the same order of magnitude.

Lastly, because series can have structural breaks, we consider the Jewell et al. (2003) panel LM unit root test that allows for two endogenously determined structural breaks. The Jewell et al. test is based on the Im et al. (2003) panel unit root test (and thus, assumes cross- 
sectional independence) ${ }^{9}$ and on the Lee and Strazicich (2003) time-series unit root test that determines the optimal number and location of breaks endogenously. All four tests assume the null hypothesis of nonstationarity.

If all the variables are integrated of the same order, the next step is to test for cointegration. Again, if a stationary linear combination of two or more nonstationary series exists, the nonstationary series are said to be cointegrated (Engle and Granger 1987). The stationary linear combination is called the cointegrating equation.

The Pedroni $(1999,2004)$ heterogeneous panel cointegration test is an extension to panel data of the Engle-Granger framework. The test involves regressing the variables along with cross-section specific intercepts, and examining whether the residuals are integrated order one (i.e., not cointegrated). Pedroni proposes two sets of test statistics: (i) a panel test based on the within dimension approach (panel cointegration statistics), of which four statistics are calculated: the panel v-, rho-, PP-, and ADF-statistic; and (ii) a group test based on the between dimension approach (group mean panel cointegration statistics), of which three statistics are calculated: the group rho-, PP-, and ADF-statistic. Pedroni $(1999,2004)$ further demonstrated that the panel PP and ADF and the group PP and ADF statistics have the best small-sample (time dimension less than 40-50) properties of the seven test statistics, and thus, provide the strongest single evidence of cointegration. Hence, we focus on those four statistics. Pedroni $(1999,2004)$ recommends subtracting out common time effects to capture a limited form of cross-sectional dependency (e.g., common business cycle shocks).

The Westerlund (2007) second-generation panel cointegration test is based on the error-correction model setup, i.e., it tests for the absence of cointegration by determining whether there exists error-correction for individual panel members or for the panel as a whole. Similar to the Pedroni test, the Westerlund test produces panel and group test statistics (two

\footnotetext{
${ }^{9}$ The literature on panel unit root tests with structural breaks that account for cross-sectional dependence too is still developing. Early evidence suggests that the additional consideration of cross-sectional dependence can reverse the findings of structural break tests alone (e.g., Snaith 2012).
} 
each for a total of four). We focus on the group- $\tau$ and panel- $\tau$ statistics since, according to Westerlund (2007), those statistics have the highest power and are the most robust to crosssectional correlation (i.e., dependence). Robust (to cross-sectional correlation) critical values for the test-statistics are obtained through bootstrapping. Both the Pedroni and Westerlund tests assume a null hypothesis of no cointegration.

Lastly, if the variables are shown to be cointegrated, then the long-run elasticities are calculated from Pedroni’s (2000) FMOLS estimator. Again, in addition to producing asymptotically unbiased estimates with normally distributed standard errors, FMOLS is a nonparametric approach in which an initial estimation calculates the serial correlation and endogeneity correction terms. Also, the FMOLS estimator is a group mean or between-group estimator that allows for a high degree of heterogeneity in the panel.

\subsection{Pre-testing results}

As discussed above, in the energy economics literature a number of researchers have found variables like GDP per capita, energy consumption, carbon emissions, population, and labor force to be nonstationary in levels but stationary in first differences for panels of developed and developing countries. For example, energy consumption, real GDP, and labor force were found to be panel I(1) for developing Asian countries (Lee and Chang 2008), Central American countries (Apergis and Payne 2009a), and former Soviet countries (Apergis and Payne 2009b); Lee et al. (2008) found energy consumption per capita and GDP per capita to be I(1) for OECD countries; Apergis and Payne (2010) found energy consumption and labor force to be $I(1)$ for OECD countries, and Narayan et al. (2007) found residential electricity consumption per capita to be $I(1)$ for G-7 countries. Thus, we have a strong a priori belief that the variables in this study should be panel I(1) as well. 
Table 3 displays the panel unit root test results for the four panels described earlier. The results for carbon emissions, energy consumption, per capita GDP, and population do not provide any compelling evidence to contradict the findings of many previous studies that have found those variables to be panel $I(1)$. The null hypothesis of nonstationarity in levels is never rejected in all four tests; whereas, the null hypothesis of nonstationarity in first differences is rejected by each test. ${ }^{10}$ Also, the table indicates convincing evidence that the novel variable tested here, share of residential energy consumption from electricity (Sh electric), is an $I(1)$ variable for all panels as well (convincing, at least for the three income-based panels). Thus, OLS regressions with the variables in levels would be inefficient and likely spurious.

Table 4 shows the results of the panel cointegration tests for the two models (carbon emissions from transport and residential electricity consumption) for all four panels. The Pedroni tests indicate substantial evidence of cointegration for both models since at least three of the four statistics are significant for each panel, except for residential electricity model and the rich countries panel (and for that panel both Westerlund statistics are significant). The Westerlund tests also indicate substantial evidence of cointegration since the panel statistic is significant for each panel, and the rejection of the null by that statistic is evidence of cointegration for the panel as a whole (a significant group statistic is evidence of cointegration for at least one of the cross-sections). Thus, there is a long-run cointegrating relationship among those environmental impacts, affluence, and population.

Table 4

4. Main results and discussion

Tables 5 and 6 show the long-run elasticities for the two consumption-driven impacts (carbon emissions from transport and residential electricity consumption, respectively) for all four panels. For both models the elasticity estimates appear to differ considerably when they

\footnotetext{
${ }^{10}$ Several additional first-generation unit root tests were applied as well. None of those results conflict with the ones displayed.
} 
are estimated from panels according to development level compared to when all countries are grouped together. To determine whether the estimated coefficients for the various panels are indeed statistically different, 99 percent confidence intervals are displayed as well. If the displayed confidence intervals of a coefficient do not overlap for two panels, then those coefficients should be statistically different at least at the one percent level. Additionally, the results from difference in means tests are displayed in the lower panels of Tables 5 and 6.

\section{Table 5}

For carbon emissions from transport, the coefficients for both affluence and urban population are not statistically different from unity for the "all countries" panel. Likewise, affluence's coefficients are not statistically different from unity for the poor and middle country panels. Affluence has a greater environmental impact than urban population in poor and middle countries; ${ }^{11}$ but affluence has a smaller impact than urban population for rich countries, ${ }^{12}$ and affluence's elasticity for rich countries is considerably, significantly smaller than affluence's elasticity estimated from the "all countries" panel (as can be seen by comparing their confidence bounds in the table). This result is not surprising since rich countries are likely near saturation in aspects like car ownership, so additional income would not increase emissions as much as adding another high-consuming person. Furthermore, both the confidence intervals and the difference in means tests show that affluence's elasticity for rich countries is significantly different from affluence's elasticity for both poor and middle countries. Yet, the elasticities for affluence for the poor and middle country panels are not statistically different from each other.

For carbon emissions from transport, urban population's influence on environmental impact has an inverted-U relationship with respect to development level. The coefficient for urban population is higher for middle countries than for poor countries, and it is higher for

\footnotetext{
${ }^{11}$ Difference in means test statistics 2.72 and 1.81 and associated p-values 0.01 and 0.07 , respectively, for poor and middle countries (results not shown in Table 5).

${ }^{12}$ Difference in means test statistic -2.78 and associated p-value 0.01 (result not shown in Table 5).
} 
middle countries than for rich countries. However, this difference in impact is statistically significant only for the rich and middle country panels - and then only at the ten percent level.

That the elasticity of affluence (income) is significantly lower for rich countries than for other countries but still positive confirms the general result from EKC studies that considered transport-driven pollutants: those studies (Cole et al. 1997; Hilton and Levivson 1998; Liddle 2004) rejected an inverted-U relationship between income and transport energy consumption.

That urban population is an important driver of transport carbon emissions confirms a general result from the STIRPAT literature. However, the finding that transport carbon emissions tend to grow faster than urban population provides some contrast to several STIRPAT papers (Dietz and Rosa 1997; Shi 2003; York et al. 2003; and Cole and Neumayer 2004). Yet, those STIRPAT papers estimated elasticities between total carbon emissions and total population and did not estimate separate elasticities for different levels of development. By contrast, Poumanyvong et al. (2012), who considered transport energy use, estimated an elasticity for (total) population of less than one for low-income countries, but estimated elasticities greater than one for both middle- and high-income countries.

Table 6

With residential electricity consumption as the dependent variable, Table 6 , for both the all countries and the poor countries panels, affluence's influence on environmental impact is considerably smaller than either urban population's or the access to/relative size of the electricity grid (share electric). This result could indicate that poor countries differ substantially with respect to electrification even when controlling for per capita GDP (poor countries are the only panel to have a coefficient of variation greater than one for share electric, see Table 2). For middle countries, share electric's elasticity is larger than affluence's too, but urban population's elasticity is quite small. Affluence's elasticity is certainly 
tempered by the share of residential energy from electricity (Sh electric), a variable that is highly related to, and indeed, probably caused by affluence (as discussed above). For rich countries all three variables have quite similar elasticities.

Considering elasticities across development levels indicates quite different nonlinearities for the three variables. Affluence's impact has an inverted-U relationship with respect to development - similar to an EKC (however, importantly, the elasticity of affluence is still positive for rich countries). Electrification is an important part of the development process, and the lower coefficient for rich countries than middle countries could, as with affluence's elasticity with respect to carbon emissions from transport, signal a saturation process. Yet, for affluence, the differences between the poor and rich country panels and between the middle and rich country panels are not statistically significant.

On the other hand, urban population's impact follows a U-shaped relationship with development. The elasticity for middle countries is an order of magnitude less than for poor countries and less than half that of rich countries - and all of these differences are highly statistically significant. That the elasticity for urban population in poor countries would be essentially one and that it would be much higher than the elasticity for both middle and rich countries reflects the fact that rural populations in poor countries would have virtually no access to electricity, unlike in middle and rich countries where gaps in electricity access between rural and urban (suburban) areas/regions should be smaller. That high elasticity for urban population in poor countries also suggests that rural to urban migration in poor countries has an important environment impact. No clear explanation comes to mind as to why the elasticity for urban population in middle countries would be so low, but perhaps this finding reflects the difficulty of defining middle countries (and thus, the diversity among those countries) over such a long time-frame (as discussed in Footnote 6). 
Meanwhile, the impact of the share of residential energy consumption from electricity has a monotonically declining relationship with development, but an apparently nonlinear one, since the share electric's elasticity for rich countries is considerably smaller than that for middle countries; whereas, the difference in elasticities is much less between poor and middle countries. Those differences across development are all statistically significant, and thus, share electric is probably masking the effect of affluence for which differences across development were insignificant to only marginally significant.

These three different nonlinear relationships (for affluence, urban population, and share electric) are displayed in Figure 1. The figure also shows the five percent error bars for each estimated elasticity (the vertical lines), and thus, it can be seen that each development level (poor, middle, and rich) has a statistically significantly different elasticity (at the five percent level) for urban population and share electric (for each panel, its upper bound is outside every other panel's lower bound). Yet, for affluence, the elasticity for rich countries is not statistically different from the elasticities of either middle or poor countries (however, middle and poor countries do have a statistically different elasticity from each other).

Figure 1

\section{Conclusions}

This paper started with the familiar stochastic IPAT (or STIRPAT) framework and used panel cointegration and Fully Modified OLS to estimate the long run environmental impacts of affluence (GDP per capita) and urban population for panels of developed and developing countries. Many of the highly trending, stock-based variables typically analyzed in STIRPAT studies, like income (GDP per capita), population, energy consumption, and emissions, are nonstationary; thus, panel OLS estimations (with the variables in levels) would produce unreliable diagnostics, as well as a high risk of the estimated relationships being spurious. Yet, few in the STIRPAT literature have addressed this potential nonstationarity, 
and only one other paper to our knowledge has exploited the possible cointegration among the variables (as is commonly done in the energy/carbon emissions-economics literature). So, by using those methods, the paper accounted for the highly inter-related and mutually causal nature of the IPAT variables, as well as for their integration properties.

Two consumption-driven impacts were considered - carbon emissions from transport and residential electricity consumption. Whether or not the elasticity for affluence was greater than that for urban population was a function of both the choice of dependent variable and the makeup of the panel (all countries, poor, middle, or rich). Also, some elasticities were statistically indistinguishable from unity, whereas other elasticities were considerably lower, depending on those same factors. Furthermore, the elasticities varied, in a nonlinear fashion, according to the development process - this pattern was particularly true for residential electricity consumption, where differences according to development (i.e., poor, middle, rich) were nearly always statistically significant. These nonlinearities themselves were diverse: Ushaped, inverted U-shaped, and monotonic patterns were revealed, again, depending on the choice of dependent and independent variables in question.

The different estimations have important implications for future emissions/energy consumption. The elasticity estimates imply that in poor and middle countries income growth should be a major driver of carbon emissions from transport. Indeed, both affluence and urban population elasticities imply substantial growth in such emissions for countries of all development levels - although slower growth for rich countries. Clearly, efforts to lower future carbon emissions from transport need to focus on vehicle technology (i.e., encouraging the adoption of more fuel efficient vehicles as well as increasing fuel efficiency). Increasing electrification should be an important driver of residential electricity use in both poor and middle countries, as will continued rural to urban migration in poor countries. By contrast, all 
three of the elasticity estimates for rich countries imply relatively low growth for residential electricity consumption (each factor having a similar impact).

The paper introduced/argued for a methodological improvement to the greater macrolevel, cross-country-development empirical analysis literature. The paper addresses the question whether the elasticities (for affluence and population) change with development; it does so by comparing estimations from panels made up of poor, middle-level, and rich/developed countries and by determining whether those estimations are statistically significantly different from each other, rather than by including a squared GDP per capita term in the regressions (and testing whether that coefficient is negative and statistically significant). The paper thereby addressed a criticism by Wagner (2008), levied on the EKC literature, that regressions involving such nonlinear transformations of integrated variables could be spurious, and significance tests based on them invalid. Similarly, the paper builds on the transport-focused EKC literature — which has rejected an inverted-U relationship between income and transport energy consumption—by explicitly determining that affluence's (GDP per capita's) elasticity for carbon emissions from transport is statistically significantly lower for rich countries than for poor or middle countries, but is still positive. Allowing for such a possibility is an additional strength of the panel-based approach.

Further, it could be argued the panel-based approach used here more accurately reflects the true development process, which seems to proceed more intermittently and in step-wise fashion than continuously or smoothly. Indeed, the typical approach analyzes all countries together (and typically with data spanning only the last 30-50 years); in doing so, it implicitly assumes that, when countries like Switzerland or USA had low levels of income years ago, those countries behaved as do - and were described by macro variables as arecountries with similarly low levels of income today; but in fact they may not, because the timing and history of the development process are quite important. For example, Bangladesh 
and Cameroon have levels of real per capita GDP today similar to those of Western Europe and the USA in $1820 ;{ }^{13}$ but few would believe or claim that those developing countries today are very similar to the Western countries of that earlier time, or that they have similar prospects for the future. The OECD countries largely began in the 1800 s the development process (e.g., the transition to lower infant mortality and fertility rates, the transition away from agriculture toward industry and then toward high value services, the move from on-site energy generation and consumption to centralized electricity grids, creation and refinement of institutions like free trade, etc.), and the various steps of that process evolved over 100 years or so. Yet, to the extent that the countries that are described as developing today have undergone or begun to undergo those steps, they have done so at a much more rapid pace and in a world with much different technologies and sets of governing institutions. Hence, separating countries according to similar current levels of development not only groups countries that are at similar levels today, but groups countries that have had and likely will have similar development paths.

\footnotetext{
${ }^{13}$ The data for this example come from Angus Maddison (http://www.ggdc.net/).
} 


\section{References}

Apergis, N. and Payne, J. 2009a. Energy consumption and economic growth in Central America: Evidence from a panel cointegration and error correction model. Energy Economics 31, 211-216.

Apergis, N. and Payne, J. 2009b. Energy consumption and economic growth: evidence from the Commonwealth of Independent States, Energy Economics 31 (2009), pp. 641-647.

Apergis, N. and Payne, J. 2010. Renewable energy consumption and economic growth: Evidence from a panel of OECD countries. Energy Policy 38, 656-660.

Apergis, N. And Payne, J. 2011. A dynamic panel study of economic development and the electricity consumption-growth nexus. Energy Economics, 33, 770-781.

Becker, Gary S \& Murphy, Kevin M \& Tamura, Robert, 1990. "Human Capital, Fertility, and Economic Growth," Journal of Political Economy, 98(5), S12-37.

Bloom, D. E. and Williamson, J.G. (1998). Demographic Transitions and Economic Miracles in Emerging Asia. The World Bank Economic Review, 12 (3), 419-455.

Carson, R. 2010. "The Environmental Kuznets Curve: Seeking Empirical Regularity and Theoretical Structure.” Review of Environmental Economics and Policy, 4(1), 3-23.

Cole, M. and Neumayer, E. (2004). Examining the impact of demographic factors on air pollution. Population and Environment, 26(1), 5-21.

Cole, M., Rayner, A., and Bates, J. 1997. The environmental Kuznets curve: an empirical analysis. Environment and Development Economics 2, 401-416.

Deacon, R. and Norman, C. 2006. "Does the environmental Kuznets curve describe how individual countries behave?" Land Economics, 82(2), 291-315.

Dergiades, T. and Tsoulfidis, L. 2008. Estimating residential demand for electricity in the United States, 1965-2006. Energy Economics, 30, 2722-2730.

Dietz, T. and Rosa, E.. (1997). Effects of population and affluence on $\mathrm{CO}_{2}$ emissions. Proceedings of the National Academy of Sciences of the USA, 94, 175-179.

Dinda, S. 2004. Environmental Kuznets Curve Hypothesis: A Survey. Ecological Economics, 49, 431-455.

Ehrlich, P. and Holdren, J. (1971). The Impact of Population Growth. Science, 171, 12121217.

Engle, R. and Granger, C. 1987. Co-integration and error correction: representation, estimation, and testing. Econometrica 55(2), 251-276.

Fisher, R. A. (1932). Statistical Methods for Research Workers, 4th Edition, Edinburgh: Oliver \& Boyd. 
Halicioglu, F. 2007. Residential electricity demand dynamics in Turkey. Energy Economics 29, 199-210.

Hilton, F. And Levinson, A. 1998. Factoring the environmental Kuznets curve: Evidence from automotive lead emissions. Journal of Environmental Economics and Management 35, 126-141.

Holtedahl, P. and Joutz, F. 2004. Residential electricity demand in Taiwan. Energy Economics 26, 201-224.

Im, K. S., M. H. Pesaran, and Y. Shin (2003). "Testing for Unit Roots in Heterogeneous Panels," Journal of Econometrics, 115, 53-74.

Jewell, T., Lee, J., Tieslau, M., and Strazicich, M. 2003. Stationarity of health expenditures and GDP: evidence from panel unit root tests with heterogeneous structural breaks. Journal of Health Economics, 22, 313-323.

Lee, C. and Chang, C. 2008. "Energy consumption and economic growth in Asian economies: A more comprehensive analysis using panel data," Resource and Energy Economics, 30, 5065 .

Lee, C., Chang, C., and Chen, P. 2008. "Energy-income causality in OECD countries revisited: The key role of capital stock. Energy Economics, 30, 2359-2373.

Lee, J. and Strazicich, M. 2003. Minimum LM unit root test with two structural breaks. Review of Economics and Statistics, 85(4), 1082-1089.

Liddle, B. (2004). "Demographic dynamics and per capita environmental impact: Using panel regressions and household decompositions to examine population and transport." Population and Environment 26(1), 23-39.

Liddle, B. and Lung, S. 2010. "Age Structure, Urbanization, and Climate Change in Developed Countries: Revisiting STIRPAT for Disaggregated Population and ConsumptionRelated Environmental Impacts." Population and Environment, 31, 317-343.

Liddle, B. (2011) 'Consumption-driven environmental impact and age-structure change in OECD countries: A cointegration-STIRPAT analysis'. Demographic Research, Vol. 24, pp. 749-770.

Liddle, B. 2012. The systemic, long-run relation among gasoline demand, gasoline price, income, and vehicle ownership in OECD countries: Evidence from panel cointegration and causality modeling. Transportation Research Part D, 17, 327-331.

Maddala, G. S. and S. Wu (1999). "A Comparative Study of Unit Root Tests with Panel Data and A New Simple Test," Oxford Bulletin of Economics and Statistics, 61, 631-52.

Martinez-Zarzosos, I., Benochea-Morancho, A., and Morales-Lage, R. (2007). The impact of population on $\mathrm{CO}_{2}$ emissions: evidence from European countries. Environmental and Resource Economics, 38, 497-512. 
Narayan, P. and Smyth, R. 2008. "Energy consumption and real GDP in G7 countries: New evidence from panel cointegration with structural breaks." Energy Economics, 30, 2331-2341.

Narayan, P., Smyth, R., and Prasad, A. (2007) 'Electricity consumption in G7 countries: A panel cointegration analysis of residential demand elasticities', Energy Policy, pp. 4485-4494.

Newman, P. and Kenworthy, J. 1989. Cities and Automobile Dependence: An International Sourcebook. Gower Technical, Aldershot, UK.

O'Neill, B. C. and Chen, B. S. (2002). Demographic determinants of household energy use in the United States. Population and Development Review 28: 53-88.

O’Neill, B., Liddle, B., Jiang, L., Smith, K., Pachauri, S., Dalton, M., and Fuchs, R. 2012. Demographic change and carbon dioxide emissions. The Lancet. Vol. 380 (9837), pp. $157-$ 164.

Ozturk, I. (2010). A literature survey on energy-growth nexus. Energy Policy, 38, 340-349.

Payne, J. 2010a. A survey of the electricity consumption-growth literature. Applied Energy, 87 (3), 723-731.

Payne, J. (2010b). Survey of the international evidence on the causal relationship between energy consumption and growth. Journal of Economic Studies, 37, 53-95.

Pedroni, P. (1999). "Critical Values for Cointegration Tests in Heterogeneous Panels with Multiple Regressors," Oxford Bulletin of Economics and Statistics, 61, 653-70.

Pedroni, P. 2000. Fully Modified OLS for heterogeneous cointegrated panels. Advances in Econometrics 15: 93-130.

Pedroni, P. (2004). "Panel Cointegration; Asymptotic and Finite Sample Properties of Pooled Time Series Tests with an Application to the PPP Hypothesis," Econometric Theory, 20, 597625 .

Pesaran, M. 2007. A simple panel unit root test in the presence of cross-section dependence. Journal of Applied Econometrics, 22: 265-312.

Poumanyvong, P. and Kaneko, S. 2010. Does urbanization lead to less energy use and lower $\mathrm{CO}_{2}$ emissions? A cross-country analysis. Ecological Economics. 70, 434-444.

Poumanyvong, P., Kaneko, S., and Dhakal, S. 2012. Impacts of urbanization on national transport and road energy use: Evidence from low, middle and high income countries. Energy Policy 46, 268-277.

Prskawetz, A., Leiwen J., and O'Neill, B. (2004). Demographic composition and projections of car use in Austria. Vienna Yearbook of Population Research 2004: 247-326.

Rosa, E., York, R., and Dietz, T. (2004). Tracking the anthropogenic drivers of ecological impacts, Ambio, 33 (8), 509-512. 
Shi, A. (2003). The impact of population pressure on global carbon dioxide emissions, 19751996: evidence from pooled cross-country data. Ecological Economics, 44, 29-42.

Snaith, S. 2012. The PPP debate: Multiple breaks and cross-sectional dependence. Economics Letters, 115, 342-344.

Solow, R. 1956. "A Contribution to the Theory of Economic Growth," Quarterly Journal of Economics, 70: 65-94.

Stern, D. 2004. "The rise and fall of the environmental Kuznets curve." World Development, 32(8), 1419-1439.

Stern, D. 2010. Between estimates of the emissions-income elasticity. Ecological Economics, 69, 2173-2182.

Suri, V. and Chapman, D. 1998. Economic growth, trade and energy: Implications for the environmental Kuznets curve. Ecological Economics 25, 195-208.

Wagner, Martin. 2008. "The carbon Kuznets curve: A cloudy picture emitted by bad econometrics?" Resource and Energy Economics 30, 3: 388-408.

Westerlund, J. 2007. Testing for Error Correction in Panel Data. Oxford Bulletin of Economics and Statistics 69(6): 709-748.

York, R., Rosa, E., and Dietz, T. (2003). STIRPAT, IPAT, and ImPACT: analytic tools for unpacking the driving forces of environmental impacts. Ecological Economics 46, 351-365.

Zagheni, E. 2011. The leverage of demographic dynamics on carbon dioxide emissions: Does age structure matter? Demography, 48, 371-399. 
Table1. Variables used in the study.

\begin{tabular}{|c|c|c|}
\hline Symbol & Definition & Source \\
\hline CO2 Transport & $\begin{array}{l}\text { Carbon dioxide emissions from transport } \\
\text { in metric tons }\end{array}$ & International Energy Agency \\
\hline $\begin{array}{l}\text { Residential } \\
\text { Electricity }\end{array}$ & $\begin{array}{l}\text { Total residential electricity consumption } \\
\text { in kilowatt hours }\end{array}$ & Ibid \\
\hline Affluence & $\begin{array}{l}\text { Real per capita GDP in USD and } 2000 \\
\text { constant prices }\end{array}$ & Ibid \\
\hline Sh Electric & $\begin{array}{l}\text { Share of residential energy consumption } \\
\text { from electricity }\end{array}$ & Ibid \\
\hline Urban population & $\begin{array}{l}\text { Share of people living in urban areas } \mathrm{x} \\
\text { total mid-year population }\end{array}$ & World Bank Development Indicators \\
\hline
\end{tabular}

Note: All variables in natural log form.

Table 2. Summary statistics by panel.

\begin{tabular}{|c|c|c|c|c|c|c|}
\hline Panel & Statistic & $\begin{array}{l}\mathrm{CO} 2 \text { transport } \\
\text { (metric tons) }\end{array}$ & $\begin{array}{c}\text { Residential } \\
\text { electricity } \\
(1,000 \mathrm{KW} \mathrm{h})\end{array}$ & $\begin{array}{c}\text { Affluence } \\
\text { (constant } 2000 \\
\text { US\$ per cap.) }\end{array}$ & $\begin{array}{c}\text { Urban } \\
\text { population } \\
\text { (millions) }\end{array}$ & $\begin{array}{c}\text { Share electric } \\
\text { (\% of total) }\end{array}$ \\
\hline \multirow[t]{5}{*}{ Rich } & Mean & 102.1 & 73.7 & 22,178 & 23.0 & 31.1 \\
\hline & Std. Dev. & 293.2 & 194.1 & 7,227 & 41.1 & 20.5 \\
\hline & Coef. Var. & 2.9 & 2.6 & 0.3 & 1.8 & 0.7 \\
\hline & Max. & $1,808.8$ & $1,392.2$ & 65,000 & 245.3 & 92.8 \\
\hline & Min. & 0.3 & 0.2 & 5,095 & 0.2 & 3.5 \\
\hline \multirow[t]{5}{*}{ Middle } & Mean & 19.5 & 9.2 & 7,621 & 16.6 & 17.0 \\
\hline & Std. Dev. & 26.3 & 13.0 & 3,402 & 24.3 & 12.7 \\
\hline & Coef. Var. & 1.3 & 1.4 & 0.4 & 1.5 & 0.8 \\
\hline & Max. & 147.6 & 90.9 & 21,992 & 161.8 & 76.6 \\
\hline & Min. & 0.04 & 0.1 & 1,667 & 0.1 & 1.2 \\
\hline \multirow[t]{5}{*}{ Poor } & Mean & 10.2 & 5.8 & 2,019 & 23.8 & 4.4 \\
\hline & Std. Dev. & 31.0 & 23.4 & 1,232 & 64.8 & 5.8 \\
\hline & Coef. Var. & 3.0 & 4.0 & 0.6 & 2.7 & 1.3 \\
\hline & Max. & 407.3 & 362.3 & 7,509 & 556.3 & 36.7 \\
\hline & Min. & 0.1 & 0.0 & 455 & 0.5 & 0.1 \\
\hline
\end{tabular}


Table 3. Panel unit root tests results.

\begin{tabular}{|c|c|c|c|c|c|c|c|c|}
\hline \multirow[b]{2}{*}{ Variables } & \multicolumn{2}{|c|}{ Im et al. W-stat } & \multicolumn{2}{|c|}{ ADF-Fisher chi-square } & \multicolumn{2}{|c|}{ Jewell et al. LM-stat } & \multicolumn{2}{|c|}{ Pesaran Z-stat } \\
\hline & Levels & First diff. & Levels & First diff. & Levels & First diff. & Levels & First diff. \\
\hline & \multicolumn{8}{|c|}{ All countries } \\
\hline $\begin{array}{l}\mathrm{CO} 2 \\
\text { transport }\end{array}$ & 0.3 & $-38.5 * * *$ & 195.4 & $1513.2 * * *$ & $-3.0 * * *$ & & 0.6 & $-6.1 * * *$ \\
\hline $\begin{array}{l}\text { Residential } \\
\text { electricity }\end{array}$ & 0.5 & $-40.2 * * *$ & 195.9 & $1560.8 * * *$ & -0.6 & $-72.0 * * *$ & -0.1 & $-8.9 * * *$ \\
\hline Affluence & 3.0 & $-24.5 * * *$ & 153.1 & $904.4 * * *$ & $-1.7 * *$ & & 2.1 & $-6.2 * * *$ \\
\hline $\begin{array}{l}\text { Urban } \\
\text { population }\end{array}$ & 0.2 & $-3.3 * * *$ & $258.1 * * *$ & & 10.1 & $-11.0 * * *$ & $-2.3 * * *$ & \\
\hline \multirow[t]{2}{*}{ Sh Electric } & -0.5 & $-44.9 * * *$ & 186.8 & $1805.1 * * *$ & $-2.7 * * *$ & & $-2.0 * *$ & \\
\hline & \multicolumn{8}{|c|}{ Rich } \\
\hline $\begin{array}{l}\mathrm{CO} 2 \\
\text { transport }\end{array}$ & 0.3 & $-19.4 * * *$ & 56.8 & $384.3 * * *$ & 0.4 & $-19.2 * * *$ & 1.4 & $-6.9 * * *$ \\
\hline $\begin{array}{l}\text { Residential } \\
\text { electricity }\end{array}$ & -0.0 & $-22.1 * * *$ & $75.0^{* *}$ & & 3.0 & $-9.9 * * *$ & 1.2 & $-4.9 * * *$ \\
\hline Affluence & -1.4 & $-15.3 * * *$ & 63.1 & $291.5 * * *$ & $-2.8 * * *$ & & 0.2 & $-1.7 * *$ \\
\hline $\begin{array}{l}\text { Urban } \\
\text { population }\end{array}$ & -0.7 & $-2.0 * *$ & 60.3 & $83.6^{* * *}$ & $-1.6^{*}$ & $-8.9 * * *$ & -0.9 & $-2.2 * *$ \\
\hline \multirow[t]{2}{*}{ Sh Electric } & -0.9 & $-25.0 * * *$ & $65.5^{* *}$ & & 0.1 & $-15.1 * * *$ & -0.2 & $-4.4 * * *$ \\
\hline & \multicolumn{8}{|c|}{ Middle } \\
\hline $\begin{array}{l}\mathrm{CO} 2 \\
\text { transport }\end{array}$ & 0.5 & $-18.2 * * *$ & 50.5 & $366.3^{* * *}$ & 0.9 & $-20.8 * * *$ & -0.9 & $-4.2 * * *$ \\
\hline $\begin{array}{l}\text { Residential } \\
\text { electricity }\end{array}$ & 0.6 & $-18.7 * * *$ & 45.5 & $367.2 * * *$ & 0.5 & $-12.1 * * *$ & 1.1 & $-4.4 * * *$ \\
\hline Affluence & 0.9 & $-11.5 * * *$ & 45.6 & $227.9 * * *$ & -0.3 & $-12.5^{* * *}$ & 1.8 & $-5.0 * * *$ \\
\hline $\begin{array}{l}\text { Urban } \\
\text { population }\end{array}$ & 1.7 & $-1.4^{*}$ & 60.8 & $96.5^{* * * *}$ & 8.2 & $-2.2 * *$ & $-1.7 * *$ & \\
\hline \multirow[t]{2}{*}{ Sh Electric } & 0.1 & $-23.2 * * *$ & 49.6 & $482.3 * * *$ & $-4.9 * * *$ & & -0.3 & $-5.6 * * *$ \\
\hline & \multicolumn{8}{|c|}{ Poor } \\
\hline $\begin{array}{l}\mathrm{CO} 2 \\
\text { transport }\end{array}$ & 3.2 & $-19.5 * * *$ & 66.1 & $610.3^{* * *}$ & $-5.5 * * *$ & & 0.4 & $-3.4 * * *$ \\
\hline $\begin{array}{l}\text { Residential } \\
\text { electricity }\end{array}$ & 2.8 & $-14.7 * * *$ & 52.2 & $427.7 * * *$ & $-5.2 * * *$ & & -0.7 & $-6.0 * * *$ \\
\hline Affluence & 4.5 & $-15.7 * * *$ & 49.3 & $395.2 * * *$ & -0.2 & $-14.7 * * *$ & 0.3 & $-4.0 * * *$ \\
\hline $\begin{array}{l}\text { Urban } \\
\text { population }\end{array}$ & -0.1 & $-3.9 * * *$ & $287.8 * * *$ & & 13.9 & $-10.1 * * *$ & $-1.9 * *$ & \\
\hline Sh Electric & 2.8 & $-26.6 * * *$ & 63.7 & $730.8^{* * *}$ & $-1.8 * *$ & & -0.3 & $-6.5 * * *$ \\
\hline
\end{tabular}

Note: Statistical significance is indicated by: $* * * \mathrm{p}<0.01, * * \mathrm{p}<0.05$, and $* \mathrm{p}<0.1$. 
Table 4. Pedroni and Westerlund panel cointegration tests for the individual models and panels.

\begin{tabular}{|c|c|c|c|c|c|c|}
\hline & \multicolumn{4}{|c|}{ Pedroni test statistics } & \multicolumn{2}{|c|}{ Westerlund test statistics } \\
\hline & Panel-PP & Panel-ADF & Group-PP & Group-ADF & Panel $\tau^{a}$ & 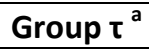 \\
\hline & \multicolumn{6}{|c|}{$\mathrm{CO}_{2}$ Transport, Affluence, Population } \\
\hline All countries & $-3.4 * * *$ & $-3.2 * * *$ & $-3.1 * * *$ & $-3.8 * * *$ & $-14.6 * * *$ & $-2.1 * * *$ \\
\hline Rich & $-2.0 * *$ & -0.6 & $-2.5 * * *$ & $-1.9 * *$ & $-8.9 * *$ & -1.9 \\
\hline Middle & $-2.0 * *$ & $-2.5^{* * *}$ & $-1.8^{* *}$ & $-4.0 * * *$ & $-14.5 * * *$ & $-2.1^{*}$ \\
\hline \multirow[t]{2}{*}{ Poor } & $-1.9 * *$ & $-1.9 * *$ & $-2.3^{* *}$ & $-2.6 * * *$ & $-7.5^{* * *}$ & -1.6 \\
\hline & \multicolumn{6}{|c|}{ Residential Electricity, Affluence, Population, Sh Electric } \\
\hline All countries & $-4.0 * * *$ & $-2.9 * * *$ & $-4.3 * * *$ & $-3.7^{* * *}$ & $-6.6 * *$ & -1.8 \\
\hline Rich & -0.4 & 0.5 & $-3.0 * * *$ & $-2.9 * * *$ & $-4.7 * * *$ & $-2.0 * *$ \\
\hline Middle & -1.1 & $-2.0 * *$ & $-1.3^{*}$ & $-2.8 * * *$ & $-2.8^{*}$ & -2.0 \\
\hline Poor & $-2.5 * * *$ & $-2.2 * *$ & $-2.1 * *$ & $-2.2 * *$ & $-4.5^{*}$ & -1.9 \\
\hline
\end{tabular}

Note: Statistical significance is indicated by: $* * * p<0.01, * * p<0.05$, and $* \mathrm{p}<0.1$.

${ }^{\mathrm{a}} \mathrm{P}$-values are robust to cross sectional correlation via bootstrapping.

Table 5. Long-run elasticity estimates and 99\% confidence intervals (C.I.) from FMOLS for carbon emissions from transport as the dependent variable. Plus difference in means tests for the Poor, Middle, and Rich sub-samples.

\begin{tabular}{|c|c|c|c|c|}
\hline & \multicolumn{2}{|c|}{ Affluence } & \multicolumn{2}{|c|}{ Urban population } \\
\hline Panel & Coeff. & 99\% C.I. & Coeff. & $99 \%$ C.I. \\
\hline All countries & $\begin{array}{c}0.999^{*} \\
(0.025)\end{array}$ & {$[0.935,1.063]$} & $\begin{array}{c}1.050^{*} \\
(0.029)\end{array}$ & {$[0.975,1.126]$} \\
\hline Poor & $\begin{array}{c}0.972^{*} \\
(0.042)\end{array}$ & {$[0.861,1.082]$} & $\begin{array}{l}0.705^{*} \\
(0.088)\end{array}$ & {$[0.475,0.934]$} \\
\hline Middle & $\begin{array}{c}1.002^{*} \\
(0.045)\end{array}$ & {$[0.884,1.120]$} & $\begin{array}{c}0.858^{*} \\
(0.065)\end{array}$ & {$[0.688,1.028]$} \\
\hline Rich & $\begin{array}{c}0.438^{*} \\
(0.033)\end{array}$ & {$[0.353,0.522]$} & $\begin{array}{c}0.682^{*} \\
(0.081)\end{array}$ & {$[0.470,0.894]$} \\
\hline
\end{tabular}

Difference in means test

\begin{tabular}{lcccc}
\hline Panels compared & Test statistic $^{\text {a }}$ & P-value & Test statistic $^{\text {a }}$ & P-value \\
\hline Poor, Middle & -0.487 & 0.626 & -1.393 & 0.164 \\
Poor, Rich & 9.973 & 0.000 & 0.186 & 0.852 \\
Middle, Rich & 10.105 & 0.000 & 1.682 & 0.093 \\
\hline
\end{tabular}

Notes: Standard errors in parentheses. ${ }^{*}$ Coefficients statistically significant at $p<0.001$.

a: $t_{c}=\frac{\beta_{1}-\beta_{2}}{\sqrt{\left(S E_{1}\right)^{2}+\left(S E_{2}\right)^{2}}}$, where subscripts refer to two sub-samples, $\beta$ to the estimated coefficients, and $S E$ to the estimated standard errors. 
Table 6. Long-run elasticities estimates and 99\% confidence intervals (C.I.) from FMOLS for residential electricity as the dependent variable. Plus difference in means tests for the Poor, Middle, and Rich sub-samples.

\begin{tabular}{|c|c|c|c|c|c|c|}
\hline & \multicolumn{2}{|c|}{ Affluence } & \multicolumn{2}{|c|}{ Urban population } & \multicolumn{2}{|c|}{ Share Electric } \\
\hline Panel & Coeff. & 99\% C.I. & Coeff. & 99\% C.I. & Coeff. & 99\% C.I. \\
\hline All countries & $\begin{array}{l}0.348^{*} \\
(0.018)\end{array}$ & {$[0.301,0.394]$} & $\begin{array}{l}0.852^{*} \\
(0.023)\end{array}$ & {$[0.793,0.910]$} & $\begin{array}{c}0.642^{*} \\
(0.006)\end{array}$ & {$[0.627,0.657]$} \\
\hline Poor & $\begin{array}{c}0.139^{*} \\
(0.018)\end{array}$ & {$[0.091,0.187]$} & $\begin{array}{c}1.022^{*} \\
(0.132)\end{array}$ & {$[0.680,1.364]$} & $\begin{array}{c}0.780^{*} \\
(0.007)\end{array}$ & {$[0.761,0.799]$} \\
\hline Middle & $\begin{array}{c}0.355^{\star} \\
(0.030)\end{array}$ & {$[0.278,0.432]$} & $\begin{array}{l}0.098^{*} \\
(0.019)\end{array}$ & {$[0.049,0.146]$} & $\begin{array}{c}0.613^{*} \\
(0.020)\end{array}$ & {$[0.561,0.665]$} \\
\hline Rich & $\begin{array}{c}0.234^{*} \\
(0.068)\end{array}$ & {$[0.057,0.411]$} & $\begin{array}{l}0.233^{*} \\
(0.024)\end{array}$ & {$[0.170,0.296]$} & $\begin{array}{c}0.286^{*} \\
(0.014)\end{array}$ & {$[0.248,0.323]$} \\
\hline
\end{tabular}

\begin{tabular}{lcccccc}
\hline \multicolumn{7}{c}{ Difference in means test } \\
\hline $\begin{array}{l}\text { Panels } \\
\text { compared }\end{array}$ & $\begin{array}{c}\text { Test } \\
\text { statistic }^{\text {a }}\end{array}$ & P-value & $\begin{array}{c}\text { Test } \\
\text { statistic }^{\text {a }}\end{array}$ & P-value & $\begin{array}{c}\text { Test } \\
\text { statistic }^{\text {a }}\end{array}$ & P-value \\
\hline Poor, Middle & -6.175 & 0.000 & 6.959 & 0.000 & 7.788 & 0.000 \\
Poor, Rich & -1.350 & 0.177 & 5.899 & 0.000 & 30.427 & 0.000 \\
Middle, Rich & 1.625 & 0.104 & -4.441 & 0.000 & 13.204 & 0.000 \\
\hline
\end{tabular}

Notes: Standard errors in parentheses. ${ }^{*}$ Coefficients statistically significant at $p<0.001$.

a: $t_{c}=\frac{\beta_{1}-\beta_{2}}{\sqrt{\left(S E_{1}\right)^{2}+\left(S E_{2}\right)^{2}}}$, where subscripts refer to two sub-samples, $\beta$ to the estimated coefficients, and $S E$ to the estimated standard errors. 


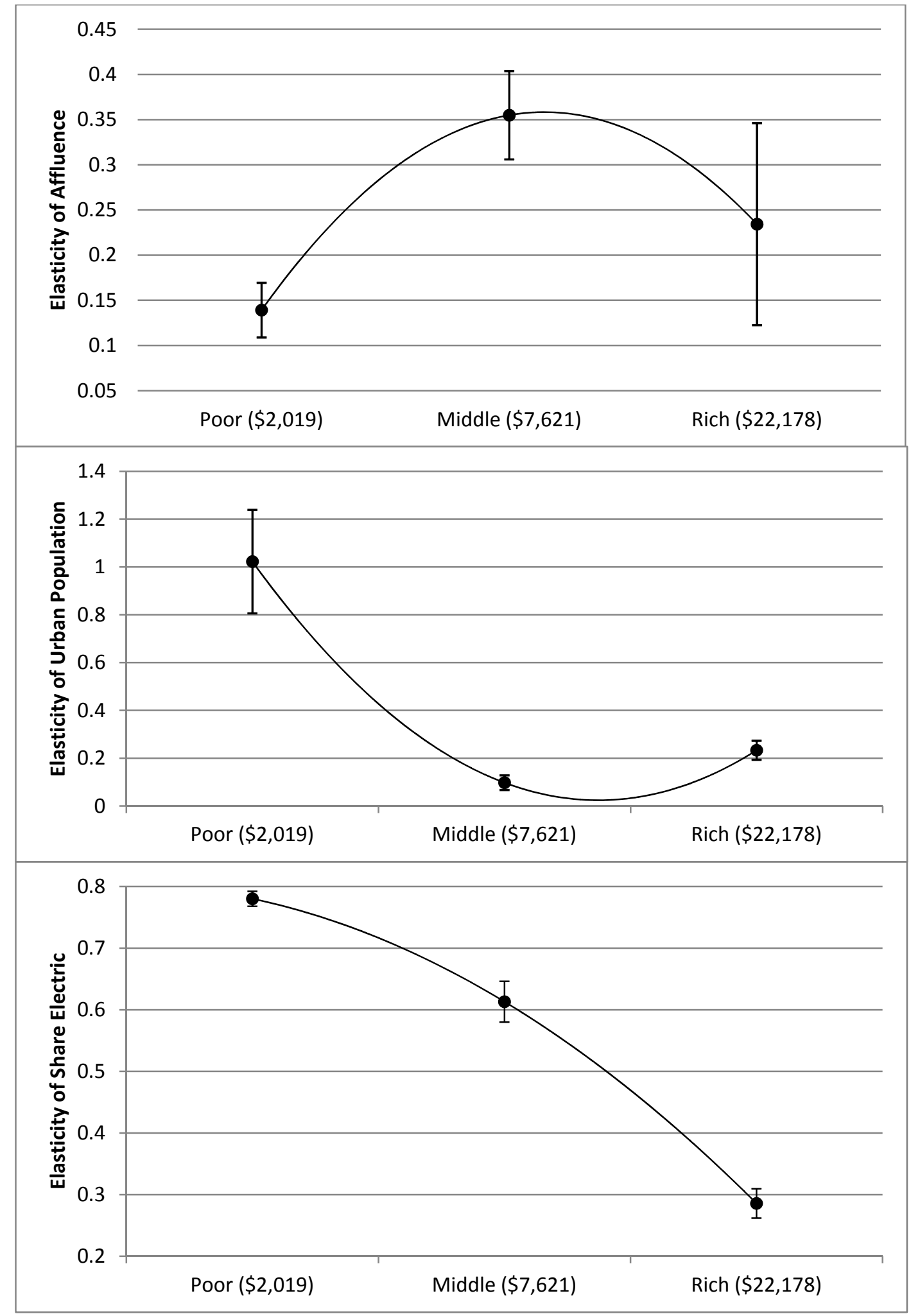

Figure 1. The change in the elasticities of affluence, urban population, and share electric according to development level. The dependent variable is residential electricity consumption. Each graph shows the elasticity estimate (the circle) and the 5\% error bars (the vertical lines) for each panel (poor, middle, and rich countries). Thus, the difference between any two panels' elasticity is statistically significant (at the 0.05 level) if one panel's upper bound is outside another panel's lower bound. A fitted second order polynomial and the average GDP per capita (in yr-2000 USD) for each panel (in parentheses) also are displayed. 
Appendix

Table A.1. Country lists for the Rich, Middle, and Poor panels

\begin{tabular}{|c|c|c|}
\hline Rich & Middle & Poor \\
\hline AUS & $\mathrm{ARG}$ & AGO \\
\hline AUT & BRA & BEN \\
\hline BEL & CHL & BGD \\
\hline CAN & $\mathrm{COL}$ & BOL \\
\hline CHE & CRI & $\mathrm{CHN}$ \\
\hline DNK & CZE & CIV \\
\hline ESP & GAB & CMR \\
\hline FIN & HUN & $\mathrm{COG}$ \\
\hline FRA & JAM & CUB \\
\hline GBR & KOR & DZA \\
\hline GRC & MEX & ECU \\
\hline HKG & MYS & EGY \\
\hline IRL & PAN & ETH \\
\hline ISL & PER & GHA \\
\hline ITA & POL & GTM \\
\hline JPN & PRT & HND \\
\hline LUX & SLV & HTI \\
\hline NLD & SVK & IDN \\
\hline NOR & THA & IND \\
\hline NZL & TTO & KEN \\
\hline SGP & TUN & LKA \\
\hline SWE & TUR & MAR \\
\hline \multirow[t]{15}{*}{ USA } & URY & MMR \\
\hline & VEN & MOZ \\
\hline & ZAF & NIC \\
\hline & & NPL \\
\hline & & PAK \\
\hline & & PHL \\
\hline & & PRY \\
\hline & & SDN \\
\hline & & SEN \\
\hline & & TGO \\
\hline & & $\mathrm{TZA}$ \\
\hline & & VNM \\
\hline & & ZAR \\
\hline & & ZMB \\
\hline & & ZWE \\
\hline
\end{tabular}

